\title{
THE IMPACT OF INFIDELITY ON FILIPINO FAMILY DYNAMICS AND YOUNG ADULT FILIPINO'S SELF- CONCEPT
}

\author{
ANDREW SIGUAN*, MAXIN FENONI THERESE ONG \& SIDNEY IRA MARIE \\ CAÑETE
}

\begin{abstract}
Parental infidelity largely influences the quality of relationships in the family. In previous researches, the focus is mainly on the dyadic marital relationship of the couples, subsequently failing to consider how this influences the upbringing and well-being of their children. This study aims to explore how adult Filipino children's discovery of parental infidelity impacted their self-concept. Using purposive sampling, the study involved fourteen (14) participants, seven males, and seven females, who were aware of their parent's infidelity. The research used a semi-structured interview schedule to gather the necessary data. Thematic analysis was used to categorize the data into two major themes: (a) Pre-infidelity Family Dynamics and (b) Impacts of Parental Infidelity. The research utilized Dr. Murray Bowen's Family Systems Theory and Self-Concept Theory by Rogers to analyse the themes and to discuss the results of the study. The research helps explain the differences in the impacts of parental infidelity on the family and on the self-concept. Further implications are discussed in the study.
\end{abstract}

Keywords: Parental infidelity; Family systems theory; Self-concept; Thematic analysis

\section{INTRODUCTION}

Marriage is said to be the most sacred commitment that any person could enter in a lifetime. It is the recognition of two people uniting intimately as equal partners in a relationship (Hafen 1983). In the Philippines, a union becomes legal by signing government-issued documents that legally record the couple's commitment to each other and through the church by being blessed by a priest and signing church-issued documents. It is said that marriage serves two purposes: unitive, which is the hand-in-hand mutual growth of the people involved in the marriage. The second purpose is procreative, giving life to another human being and taking care of these people (Browning 2003).

Asking someone his or her hand for marriage is the easiest part of the process; keeping and maintaining the harmonious and lasting relationship between two partners is the hardest part of it all. Marriage takes a lot of work, commitment, and time. It is not just fun and games as attested by numerous married couples. Each individual's personality brings into the marriage is unique, therefore making each marriage unique (Stangor et al. 2014).

For most, partners advance into the married life with such excitement about the future ahead of them, and although it is filled with happiness and fulfillment, hardships are inevitable (Lerman 2002). Some married couples overcome the challenges by extensive decision-making, the division of work at home, and comforting the emotional fatigue of one another, while some, unfortunately, grow apart both physically and emotionally. When things go south, these couples would resort to separation, which means that they would be living in different homes 
but are still technically and legally married to each other, or resort to divorce, which means that the couple's marriage has officially and legally been ended.

There seems to be a common thread tying marital dysfunction; in other words, the relationship is simply not working for different reasons such as one partner suffering from substance abuse, the financial troubles, the lack of commitment by either one or both of the persons involved in the marriage, and the endless and continuous arguing and misunderstanding between the two (Margolin 1985; Abbott et al. 1995; Leonard 2002; Bradbury \& Weiss 2006). Perhaps what could be even more traumatic than all of these problems combined is when one or both married individuals commit infidelity.

The overwhelming emotions, some of which are universally felt or shared by persons with the same experience of being cheated on, include feelings of mistrust, which are expressed through regret, knowing how much trust was placed into the marriage and was wasted; feelings of disappointment, which is expressed through thoughts of what-ifs and usually driven by the crushed image of his or her partner (Schneider et al. 2012).

It is apparent how infidelity affects the psychological state of both partners involved in the cheating relationship and how an experience of infidelity ultimately shapes future involvement in both romantic and friendly relationships with others (Peluso 2007). However, given that cases of infidelity, most specifically in the Philippines, happens in the family context, there are children involved in these stories of infidelity and sordid affairs. It is clear that people have turned a blind eye to the effects of infidelity on the child.

The researchers believe that parental infidelity is happening at home influences the quality of the parent-child relationship, in more ways than one, and the adult child's relationship with friends and future endeavors with romantic relationships. The researchers are convinced that the adult child's experience with parental infidelity has an impact on their self-concept, which could lead to other psychological problems or mental health concerns, and that the gender of the adult child who discovered parental infidelity in their homes plays a huge part in the way they interpret the experience. Indeed, even with our certainty of how parental infidelity affects the adult child, we believe that they have different ways of coping with the experience.

This study primarily asks: What are the experiences of adult Filipino children who are aware of the infidelity occurring or that occurred within their family? One of the main significances of the research is that there has been little to no researches written on the topic in the Philippine context. The research would contribute to the literature that could be used as supporting research to future similar studies. The study would provide rich data on the impacts of parental infidelity that can bring light to new knowledge to topics that may have otherwise go unnoticed.

Another significance of this research is that it highlights the impact of parental infidelity on a child's self-concept. Through the years, researchers have been focused on the mental and psychological effects of infidelity to the spouse being cheated on or to the parent that experienced the infidelity. The questions that will be asked to the participants will serve as some form of cathartic therapy. Participants can release their emotions and thoughts, decreasing the tension they feel about the subject, and experience fewer negative emotions when talking about it. By narrating their experience, they would also realize the steps they have taken in handling the family situation and eventually see their growth from a painful experience.

\section{LITERATURE REVIEW}

The family is the most essential element in society. It is the smallest unit of society, which makes it critical and significant in the development and maintenance of society (Enrique, Howk 
\& Huitt 2007). The definition of a family can be seen by three factors: family structure, task orientation, and transactional process. The family structure defines the family on how it is composed, whether, from procreation, parents and their children, biological relatives, or those people united through biological legitimacy or legal legitimacy. Task orientation or psychosocial task defines the family as a unit and how it works collectively towards achieving the needs of the unit as well as the support development of the members. The transactional process defines the family as a group of individuals with shared intimacy who generate a sense of home and group identity, strong loyalty, and emotion for one another. It has a common history and a shared vision of a future (Wamboldt \& Reiss 1989). All these lenses perceive the family as a working and collective system or commonly known as a family system. The interest of many psychiatrists and psychotherapists on whether it might be beneficial to consider the individual as an existing component in a special kind of ecological system gave birth to the idea of a theory on family systems (Bavelas \& Segal 1982).

The Family Systems Theory states that a family functions as a cohesive emotional unit which looks at a family as a system in which each member plays a certain role and must follow protocols within the unit. This theory focuses primarily on the interaction between the family members and between the family and other systems rather than focusing on one member alone. Bowen viewed an individual functioning in the context of relationships that each individual's emotional relationships are closely interconnected with one another. Furthermore, this theory believes that a change in one family member can influence the entire system (Kerr 2000).

The typical pattern in much of the world in terms of family structure would be a nuclear family. This family structure consists of a mother, father, and their offspring. The extended family, on the other hand, includes grandparents, aunts, uncles, nephews, and nieces. This kind of household does not play a prominent role in socialization and on an individual's well-being as much as that of a nuclear family (Arnett 1995).

\section{Different Definitions of Marriage}

The institution of marriage has been around since the beginning of time. According to Wimalasena (2016), the institution of marriage has a distinctive place in the realm of institutions. It is instrumental and contributory in perpetuating society through the regulation of conjugal and filial ties. The basic definition of marriage is anchored on the biological perspective, which describes marriage as a personal association between a man and a woman and a biological relationship for mating and reproduction (Wimalasena 2016). In ancient times, marriage was supposedly a contract in which a woman was given to a man as property, primarily as part of political, social, or business endeavours (Goga \& Niţă 2019).

Marriage is not a smooth ride. There will come a time when a couple would have fits and arguments about how they manage their households. The usual disadvantages of having married parents are rooted in the experiences of marital conflict. The number one disadvantage of having married parents is when couples fight in the household, especially involving physical or verbal expressions, children are likely to copy the same behaviour. According to developmental science, households with high levels of conflict are linked to children's physical, emotional, and social problems later in life (Gillett 2016). Passive fighting of married couples also takes effect on the developmental growth of a child. Studies have shown that there is a long-term effect of parental withdrawal that is more disturbing than open conflict. Children who experience passive fighting perceive that something is wrong, resulting in stress because they do not understand the cause of the tension in the household, which makes it harder for them to adjust to the situation (Divecha 2014). One big issue that arises with married parents is the possibility of divorce. According to Divecha (2014), if married parents divorce when 
their children are at a young age, these children are more than likely to have poor relationships with their parents when they become adults.

\section{Existing Knowledge on Infidelity}

Infidelity has been a recurring problem in marriages. It is one of the major factors that cause significant challenges for couples and is known to be the most difficult problem to resolve in therapy. Not all people have the same views on what infidelity is; because there is no single definition for infidelity, people have different views on what behaviors or level of involvement can be considered an act of infidelity. Due to this discrepancy of opinions makes the resolving and healing process of the problem all the more difficult (Schonian 2013).

Fife, Weeks, and Gambescia (2008) believe that when people enter into marriage or any committed relationship, it is mainly characterized by an explicit or implicit commitment that considers the intimacy that includes both sexual and emotional fidelity to one's partner. Moreover, infidelity is the betrayal of the implied or stated commitment of the partner's intimate exclusivity. It is the emotional and/or sexual intimacy one partner shares with another person outside their marital relationship without the knowledge or consent of the other partner.

According to Schonian (2013), there are three variations of how an individual can commit infidelity; physical infidelity, emotional infidelity, and cyber infidelity. Physical infidelity is also known as sexual infidelity. The main definition of this variation of infidelity is when a married individual engages in sexual intercourse or activities with another person other than one's partner (Whitty \& Quigley 2008). Hertlein, Wetchler define emotional infidelity, and Piercy (2005) as a married individual who falls in love, shares emotional intimacy and bond, and/or spends intimate time with another individual outside his/her marital relationship. The third variation of infidelity is cyber infidelity. It is characterized by using technological advances like smartphones or laptops, any technological medium of communication, to engage in sexual or emotional interactions with other people outside an individual's marital relationship (Young et al. 2007).

When infidelity occurs, people tend to prioritize the feelings and well-being of the betrayed spouse, but what they do not know is that there is a much more significant issue that people must be concerned about. The children of these couples are the silent victims of marital infidelity. They are called children of infidelity. These children react to marital infidelity with intense feelings of anger, increased anxiety, guilt, sadness, and confusion (Callander 2015). According to Nogales (2009), there are six common reactions of children towards the infidelity of a parent (1) loss of trust, (2) broken concept of love and family, (3) feelings of guilt when the child knows about the infidelity, (4) anger and ambivalence towards the cheating parent, (5) feelings of resentment towards the cheating parent and (6) they act out, they may exhibit behavioural problems during childhood, sexual acting out during adolescence, intimacy problems or sexual addiction during the adult years.

Infidelity is a common phenomenon in marriages (Atkins et al. 2001), reflecting its tremendous data of married couples engaging in infidelity. As cited by Negash and Morgan (2015), there is a range of $2 \%$ to $33 \%$ of couples employed in extramarital affairs, depending on the particular data source used. Its pervasiveness in today's society raises concerns in the family, intrapersonal conflicts, violence, and psychological distress. While there is a sizeable minority of couples who are affected by these adverse outcomes, children, on the other hand, are also not exempted from the results of parental infidelity; instead, they may also be exposed to increased conflict such as disordered eating in adolescent daughters (Salafia, Schaefer \& Haugen 2013).

Moreover, the effects of parental infidelity on children can differ based on the child's gender, age, and even culture (Lusterman 2005). Compared to young children and 
preadolescents, adolescents have a lesser probability of blaming themselves when exposed to parental infidelity (Duncombe \& Marsden 2004). Although adolescents are less likely to blame themselves, they may still experience difficulty processing the causes and implications of parental infidelity. Subsequently, adolescents' confusion may turn to fear in which can be internalized. Adolescents with developed cognitive capabilities may place more responsibility on one parent and exhibit "unilateral loyalties and create dysfunctional triads that can continue through adulthood" (Negash \& Morgan 2015).

Brown (1991) suggests that an adolescent who feels overburdened often goes through parentification. The added pressure of caring for the parent who did not commit infidelity may elicit feelings of resentment and anger toward the parent who engaged in infidelity. An adolescent with a 'parentified' role may feel obliged to control the aspects of their environment. Wardle (2002) stated that "infidelity robs children of childhood and the joys of completely trusting the most important authority figures in their lives." Subsequently, some children may react angrily to the parent who threatens the integrity of the family (Wardle 2002).

Past research suggests that a disturbance in parents' sexual relationship can be noticed by the children and influence their erotic map (Schnarch 1991). Adolescents who notice these sexual disruptions may cope with their emergent sexuality (Duncombe and Marsden 2004). In Minuchin's (1974) work, he declared that diffused generational boundaries might have implications in children's actions. Furthermore, children are more likely to experience problems in building a sexual identity. (Wallerstein and Kelly 1980)

In the Philippines, infidelity as a topic is considered taboo, and studies on the subject are insufficient. Some researches have also revealed increasing frequencies of marital infidelity (Ong et al. 2014). Infidelity stretches from having a mistress to causal relationships and is a commonly perceived incident performed by males. As the years passed, a solid objection to this kind of practice was observed among Filipinos. Based on a 1991 survey conducted by the Social Weather Stations (SWS), a resounding 85 percent mentioned that it is "always wrong" to have extramarital relations. However, Filipinos still involve in infidelity practices in defiance of the negative outlook to this kind of behavior. Also, infidelity studies and data are scarce in the Philippines because of negative predispositions (Abalos 2011).

According to a 2009 report from the National Commission on the Role of Filipino Women, two percent of women and 36 percent of men are involved in marital infidelity, making it a leading cause of stress among Filipino couples (Lee 2015). A recent study on parental infidelity highlighted the effect of parental infidelity on young adults in instituting romantic relationships. The researchers discovered that the impact of parental infidelity on developing connections in the late teenage years is a process and is best illustrated through a cross. The concepts of "reaction, circumspection, self-recognition, stagnation, and overturn" were all created. Another research conducted by Gonzales et al. (2004) focused on resilience patterns in Filipino wives ' behaviors to their husbands' infidelity by looking at various demographics, experiences, and religious practices. Their study revealed that depression and worry about finances were the main issues of the wives. Although with spiritual support and problem skills, the wife sees herself as a victim who is only doing what she must survive, but rather as a conqueror leading her own life. An additional recent study explored the perspectives and experiences of siblings during the time their mother engaged in an extramarital relationship. The researchers interviewed and tested the siblings to gather their ideas and attitudes towards an ideal family, their parents, marriage, trust, and infidelity. The study's findings suggest that adultery affects both parents and children (Batara 2018). As mentioned earlier, there is little to no researches written on infidelity and self-concept in the Philippines context, which makes this paper a significant contribution to the infidelity literature in the Philippines. 


\section{Research Gap}

The variables that are reviewed in this section, the family, infidelity, and self-concept, are those that the researchers will be focusing on. Despite the literature provided, the researchers noticed a gap in the research found, the impact of the discovery of parental infidelity on the adult Filipino children's self-concept. The researchers aim to fill this gap to further contribute to the existing body of knowledge on parental infidelity.

\section{THEORETICAL FRAMEWORK}

\section{Family Systems Theory}

The Family Systems Theory was developed by an American psychiatrist, Dr. Murray Bowen (1913-1990). This theory provides a new paradigm for the conceptualization of human behavior and the treatment of human problems. It states that a family functions as a cohesive emotional unit. It is a theory about relationships. It looks at a family as a system in which each member plays a specific role and must follow protocols within the unit. Bowen viewed an individual functioning in the context of relationships that each individual's emotional relationships are closely interconnected with one another (Bowen 1978). There are the eight interlocking concepts in this theory, which are (1) Differentiation of self, (2) Triangles, (3) Nuclear family emotional system, (4) Family projection process, (5) Emotional cut-off, (6) Multi-generational transmission process, (7) Sibling position, and (8) Societal regression (Bowen 1978; Haefner 2014).

\section{Self-concept: Carl Rogers}

The term "self" is a word that is constantly being used to refer to one's self-esteem, self-image, and others. In actuality, there are multiple ways to describe the self. Schwartz (1977) described the self as how an individual judges the self, how an individual thinks about others, how one imagines and thinks about their own body, and what one believes others think of the self. In addition, the self is defined as a "person's essential being that distinguishes them from others, especially considered as the object of introspection or reflexive action."

How is the self-concept constructed, and how does it change throughout development? The concept of the self during infancy is non-existent. In this sense, the infant does not have even the most rudimentary notion that he or she is separate from the mother. Harter (1983) believes that that the infant gradually advances through stages of self-knowledge and selfawareness. He also added that awareness of the self only begins to emerge during the first year of infancy with the appreciation that one's body is separate from the mother and that one is an active and causal agent in space (Harter 1988). Self-descriptions in early and middle childhood differ from concrete, observable behaviours (Montemayor \& Eisen 1977) to the emergence of trait labels. Trait labels include adjectives such as popular, intelligent, and helpful. Children at this stage combine a number of specific behaviours to a generalized concept of the self (Harter 1988). During adolescence, a major component at this stage would be the use of abstract concepts in making references to the self. Rosenberg (1979) stated that adolescents describe their psychological interior as characteristics that define the inner world of one's feelings, thoughts, and personality.

The definition of self-concept has been approached from several angles. In Carl Rogers' theory, the "self" is considered a central construct. As cited by McLeod, it is defined as the "organized, consistent set of perceptions and beliefs about oneself." Rogers believes that the 
"self" develops through interactions with others and involves awareness of the being and functioning (Pescitelli 1996). An individual's self-concept can be influenced by two primary sources, which are one's childhood experiences and evaluation of others. In his client-centered therapy, Rogers postulated that the success of therapy depended upon change or reorganization of the self-concepts held by the client. His therapy was formulated through the organization and functioning of the self. Rogers further postulated that the self is formed as an outcome of interacting with the surroundings, particularly as a result of evaluation interaction with others (Maslow 1956). Experiences that occur in the life of an individual control the development of the self through "(a) symbolized, perceived, and organized into some relationship to the self; (b) ignored because there is no perceived relationship to the self-structure; (c) denied symbolization or given a distorted symbolization because the experience is inconsistent with the structure of the self."

\section{METHODOLOGY}

The study utilized a qualitative approach to capture expressive information that cannot be obtained through a quantitative approach. The researchers believe that utilizing a qualitative approach is more appropriate for the subject matter and would bring out more expansive data that would enrich the findings of the research. To explore deeper into the aspects of the topic and probe more on the answers, a semi-structured questionnaire was used to interview the participants. The researchers conducted a one-on-one interview with the population of interest to obtain the data that will be used in this study.

The participants of this study are composed of males and females varying from ages 18 to 35 years old. The age range is based on research conducted by Kristen H. Greene (2006), where it was pointed out that young adulthood is the period wherein individuals begin to form intimate and committed relationships. They begin to get deeply attached to people outside of their families. Seven males and seven females were chosen as participants of the study, totalling 14 participants, which was selected by using purposive sampling. The participants of the study fulfilled the study's following criteria: (a) young adult (aged 18-35), (b) a resident of Tacloban City, (c) have lived six months prior or currently living with biological parents, and (d) aware of the infidelity occurring or that occurred within their family.

The materials used in the study are the following: an informed consent addressed to the participants, a semi-structured interview guide, an audio-recording device, pens, and papers during the data collection proceedings. The interview guide was translated from English to Waray-waray to cater to the language used by the participants. A pilot study was conducted before the formal data gathering to ensure the effectiveness of the interview guide and the procedures of the study. By doing so, the researchers were able to discover if the questions from the interview guide are easily understandable and sufficient enough to provide the researchers significant information on the given topic.

The data gathered in this study were analysed through thematic analysis. Thematic Analysis is used for identifying, analysing, and reporting patterns (themes) within data. There are six phases in doing thematic analysis which would be utilized by the researchers as a guide: (1) familiarize the data, (2) generate initial codes, (3) search for themes, (4) review themes, (5) define and name themes, and (6) produce the report (Braun and Clarke 2006). To illustrate the strength of the coding scheme, the researchers utilized inter-rater reliability in coding the data. The researchers played the role of the two raters, wherein they coded the data and categorized them into various themes separately. After which, the researchers met, compared their coding, and generated the final results. This tool helped the researchers test the objectivity and how consistent the coding is done (Osika 2017). 


\section{RESULTS AND DISCUSSION}

Table 1. Profile of the research subjects.

\begin{tabular}{ccc}
\hline Pseudonym & Age & Sex \\
\hline Jemari & 20 & Female \\
Hyacinth & 24 & Female \\
Abigail & 23 & Female \\
Yeri & 22 & Female \\
Natalie & 24 & Female \\
Royce & 21 & Female \\
Jessie & 18 & Female \\
Mark & 18 & Male \\
David & 19 & Male \\
Jacob & 22 & Male \\
Sean & 22 & Male \\
Hunter & 23 & Male \\
Jay & 24 & Male \\
Lester & 19 & Male
\end{tabular}

This qualitative descriptive research was set on exploring and understanding the experiences of adult Filipino children who are aware of the infidelity happening in their families. A brief profile of the respondents is presented above (see Table 1). Pseudonyms were utilized to protect the privacy of the respondents. The respondents were questioned about the psychological effects of the parental infidelity that they experienced, how these experiences affected their self-concept and how they coped with the changes in their self-concept. The subject matter was specifically examined using a semi-structured questionnaire that utilized the theoretical rationale of the Family Systems Theory.

This section of the research displays the themes and sub-themes that emerged from the accumulated responses of the participants. The two major themes include (1) Pre-infidelity Family Dynamics and (2) Impacts of Parental Infidelity. The developed sub-themes are also presented below in Table 2.

Table 2. Themes and subthemes of the results from the thematic analysis.

\begin{tabular}{cl}
\hline \multicolumn{1}{c}{ Themes } & \multicolumn{1}{c}{ Subthemes } \\
\hline & Pre-Infidelity Mother-Child Relationship \\
Pre-Infidelity Family Dynamics & Pre-Infidelity Father-Child Relationship \\
& Pre-Infidelity Sibling Dynamics \\
& Relationship with Friends Pre-Infidelity \\
\hline & Post-Infidelity Family Dynamics \\
Impacts of Parental Infidelity & Psychological Effects of Parental Infidelity on the \\
& Child \\
& Impacts of Parental Infidelity on the Participants' Self- \\
& Concept \\
\hline
\end{tabular}

Theme 1: Pre-infidelity Family Dynamics

It is said that the family unit is the foundation of all social relationships in the Philippines. In the traditional family system, the role of the family is said to be "pervasive." This means a family's influence exerts and extends to other social organizations in a person's life. With this, it can be deduced that one's family becomes the socialization agent of its children (Torres 1995).

The theme focuses on the perceived family dynamics of the participants prior to the discovery of their parent's infidelity. This includes how the participants described their families 
as a cohesive unit, how they got along, and how functional they were. This was explored in order to provide insight as to how the infidelity affected their family dynamics after the discovery and whether or not the gravity of the changes would depend on the relationship of their family prior to the cheating. When the participants were asked about their previous experiences with their families, 3 out of 14 participants described their families as the ideal type wherein the family enjoyed each other's companies and were supportive of each other. As stated in a journal article written by Garo-Santiago, Mansukhani, and Resurreccion (2009), a person's family is a primary source of life satisfaction and well-being.

The participants characterized their families as genuinely happy and very contented with what they had. They expressed how great their family dynamics were and how they had meaningful interactions with each other. Jemari, a 20-year-old student and an only child, described their family as the ideal family when compared to the families of their relatives, whose fathers were also involved in infidelities of their own.

\begin{abstract}
"Before nag cheat an akon tatay, let's just say feeling ko ngan han an akon mga patod, kami an ideal ba na family, han dida han amon ha father side kay ha father side man gud puros may problema, may mga daddy issues kamin tanan, tas akon pinakalast na nakasabot nga ako geap ngayan so, feeling ko kamin pinaka okay ha pera ito, 6 na kuan, families ha father side. "[Before my father cheated, let's just say that my cousins and I felt that my family was the ideal family. My relatives from my father's side had problems with their fathers, we all had daddy issues, I was the last to know that I had the same problem with my father as well, I felt that we were the most "okay" out of the 6 families.]
\end{abstract}

Mark, whose father worked outside the country, added that despite his father being away from home, he could still describe his family as normal and typical as other families and is completely satisfied with what they had.

"Normal, typical happy family. Hi Papa adto abroad tas kami happy la kami. Tas you know we have the resources man tas yun happy lang." [Normal, typical happy family. My father was abroad, and we were still happy. We had enough resources, and we were happy.]

Some families are not that affectionate nor openly comfortable with each other, but despite having this type of relationship, the family continues to function normally. 3 out of 14 participants describe their families as a normal household, wherein their family members are not close with each other but also not estranged to the point that it cuts off the interaction.

Sean, a first-year college student, expressed that his family, composed of 6 members, usually interacts with each other during meals and after which each member does their own individual activities without minding each other. It is important to note that some families experience conflicts between their members, which results in some form of hostility existing between the family members. 2 out of 14 participants characterized their families as unconventional, wherein the conflicts existing between their parents often radiate and affect the relationship of those outside their conflict.

Abigail experienced various conflicts between her parents, which led her to see their family as disorganized or chaotic. She recalls how her parents fought with each other frequently over different matters and even over petty concerns.

In Bowen's concept of 'triangling,' it is said that when tension arises between two persons in a family, triangling occurs when this said tension is passed on to a third person in the family. It is believed that the dyad is able to resolve the issue safely when they shift anxiety away from their relationship and on to the third party (Haefner 2014). However, when the dyad does not try to resolve their issues with the help of a third person, the researchers believe that the tension, stress, and anxiety from the dyad's continuous issues ultimately and inevitably spread throughout the whole family unit. 
Some participants expressed that a personal problem of one parent also creates a problem for another member of the family. Lester is a middle child whose father was described as inattentive and an alcoholic drinker and whose mother carried the burden of the responsibilities left by their father. He explained how the role of his father was not maximized and how his father did not take care of the children as a father should have.

In Arellano-Carandang's book, she believes that there arises a "tagasalo" or a person who assumes responsibility when a family experiences difficult challenges. In the case of Lester, his mother assumed the responsibilities of his father since he could no longer do so due to being alcoholic and inattentive (Arellano-Carandang 1995). Moreover, in Bowen's Family Systems Theory, he introduced the concept of the nuclear family emotional system. In a functional family system, every member of the family has an expected role. However, when one family experiences a dysfunction in one spouse, the whole family system experiences stress and consequently results in the changes of each member's role to compensate for the abandoned responsibility (Haefner 2014).

\section{Pre-Infidelity Mother-Child Relationship}

The theme's attention is focused on the perspective of the participants regarding their motherchild relationship before they discovered infidelity. The questions related to the theme revolved around the type of relationship the participants had with their mothers prior to the discovery, how they saw and described their mothers during that time and how intimate they were with each other. These questions are important to see how their relationship affected the actions done by the participants upon the discovery and knowing the gravity of the effect it had on them.

It has been emphasized that the mother-child relationship plays a significant role in child development (Simpkins et al. 2014). It was noted that the mother-child interaction during the early years determines the basic personality of a child. This relationship is usually branded by warmth, nurturance, and protectiveness. However, it is also characterized by unique strictness and control (Espina 1996).

Three female participants stated that the bond with their mothers was stronger than any other relationship they had, to the extent that they consider their mothers as their own friends. They can engage in comfortable conversations with their mothers, which tackle different dayto-day life experiences. The participants viewed their mothers as the perfect mothers, their confidants, and their primary support system. The participants also acknowledged that despite having strict mothers while growing up, this did not hinder them from developing a tight-knit relationship with each other.

Some people are not open to showing their physical affection to their mothers. Despite having this type of relationship, 3 out of 14 participants do not feel that their mothers somehow lack in their relationship; rather, they still feel that their mothers care for them and that they are loved. They still view their mothers positively and are still had meaningful interactions with them.

Mark, when asked about the quality of their relationship with his mother, expressed that he grew up with a strict mother who showed them tough love while growing up. Despite not hearing the occasional I love you's, Mark still sees that his mother cares for him through her advice and when she reprimands him.

It is important to note that some people do not have a great relationship with their mothers. The children with this type of relationship are detached from their mothers emotionally and physically. The participants (one female and two males) characterized their relationships as cold and with little communication. There were no bonding activities or moments that the participants shared with their mothers unless necessary, such as eating their 
meals. Abigail stated that her mother was always at work, and when she came home, she was too tired to bond with the family. She pointed out that she knew her mother had a favorite child among the family. She said she would often get into fights with that sibling which resulted in a strained relationship with her mother.

As stated by Haefner (2014) in her journal article, "people in a fused relationship react emotionally without being able to think through or talk about choices with the other person." In the case of Abigail, her fused relationship with her mother and the discovery of her mother's favorite child in the family led her to pick a fight with the said sibling instead of rationally discussing the issue with her mother. Because of their fused relationship, a possible threat to this relationship led her to react emotionally and irrationally. David, an only child, expressed that his mother's strictness became the reason for their lack of intimacy with each other. He recounted how he did not want to tell his mother about his grades because instead of being comforted, he would face his mother's nagging, and she would become angry at him, to the point that he would be accused of doing drugs.

\section{Pre-Infidelity Father-Child Relationship}

The participants were also asked about the type of relationship they had with their fathers prior to the discovery. This was noted in order to provide context as to whether or not their relationship with their fathers affected how they handled the infidelity and how much the infidelity affected them.

On the other end of the pole, Liwag (1998) characterized the father-child relationship in Filipino families as authoritative, restrictive, and controlling. It was observed that children would show "greater submission and deference" to their fathers than to their mothers. It was also found that children and adolescents would report a lack of emotional intimacy or closeness with their fathers.

Contrary to the common notion, three participants stated that they had a very strong connection with their fathers. They said that they consider their fathers as more than just a parent, they see their fathers as their best friends. The participants trust their fathers openly and are certain that their fathers will have their backs when they encounter problems or difficult situations.

There were participants who described their relationship with their fathers as a normal relationship. They both fulfill the duties of being a parent and a child. The interaction between the participants (one male and one female) and their fathers remains civil, they do not show much affection, physically and emotionally, to each other, but they know that they can trust each other. However, some participants have described their relationships with their fathers as distant and cold. 4 out of 14 participants shared that they see their fathers only as providers and would only approach them more on discussing financial matters and material needs. These participants see their mothers as the other counterpart. They approach their mothers more for their emotional needs and comfort.

David stated that he and his father were never that close despite the common notion that fathers and sons would be the closest in the family. He expressed how his and his father's relationship only involved sufficing his personal needs. Yeri also shares the same sentiments with her father; although she is not close with him, she still appreciates that her father continues to provide for their family very well and that she respects him greatly.

\section{Pre-Infidelity Sibling Dynamics}

Siblings share almost the same environment growing up and experience their first developing years together. These commonalities between them create a stronger bond and make their 
relationship more valuable. The questions related to this section revolve around the relationship the participants have with their siblings, how close they were with each other and how they saw or were viewed by their siblings during that time.

The relationship of three (3) male participants and their siblings is said to have close sibling dynamics. The siblings are physically intimate with each other and are able to express their emotions towards each other. An example of this is David, who has stepsiblings from the first family of his father, "I am very thankful that they treated me as a sibling.... that's why I love my siblings very much because they treat me as a normal sibling."

In a journal article that was written by Howe and Ross (1990), a friendly sibling relationship is achieved when the siblings are able to directly talk about their feelings and thoughts with each other. They also believed that this quality of relationship would be consistent across time.

Some participants (2 out of 14) feel that their relationship with their siblings is just the "normal" type of sibling relationship. They would describe it as friendly, in a way that the participants can have fun with their siblings, but they describe their relationship as less intimate than others. Despite having these conditions, the participants know that they have and will have each other's backs when needed. However, there were participants that did not have close ties with their siblings. They stated that they showed little affection and were not emotionally invested with each other. Some reasons for this type of relationship include a large gap in age and gender of the siblings. Although there is a lack of intimacy between the siblings, they are still effective as a working unit together.

\section{Relationship with Friends Pre-Infidelity}

It was concluded in Debra and Wendy's (1998) journal, Assessing Children's Peer Relationships, that children's early peer relationships are significant to their social functioning. They are critical in a child's development of adaptive and maladaptive behaviors. The section focuses on the type of relationship the participants had with their peers before the time of discovery, if the child had any. It will provide information on how the relationship the participants had with their peers would affect how they dealt with the discovery.

Two male participants recalled how they had close ties with their friends before the discovery of the infidelity. Lester, who was just in grade school at the time of the discovery, had already forged great ties with his best friend since his childhood. He recalled how he always slept over at his best friend's house and played basketball with him always. Sean also shared the same experience. He said that the only time he would go back to their house was when it was time for their meal. When asked about his reasons why he usually spent time at his friends' houses rather than his own, he responded, "Whenever I encounter problems, I first share it with them because they know how to comfort me and because I enjoy spending time with them."

Most participants were not given a chance to forge friendships outside the family. Many of them considered themselves friendless during those times. Some reasoned out that it was because of the time the infidelity happened. The participants did not consider their classmates or playmates as friends because of the lack of communication as well as intimacy in the relationship. Jay recounted her memories of her first friends before the discovery and said, "All I remember is, I don't know if it was because of my age, I remember playing with my friends, but because we were getting older, we never really played that much right after." Jessie, on the other hand, believed that she did not have many friends during that time because of her personality. She acknowledged that she was not that friendly during those years and did not prioritize friendships with her peers. 


\section{Post-Infidelity Family Dynamics}

This sub-theme focuses on the changes in the family dynamics after the cheating occurred based on the participants' narratives. Certain questions such as the effects of the infidelity to each family member, along with the impacts to various facets of the self, were asked in order for them to reflect on how the infidelity affected themselves, as well as the effects on the way they interact with people. This section may be considered the center of themes for the reason that it pinpoints the outcome of the infidelity to the people affected and participants thus turn to these thoughts- positive or negative- to undertake future situations alike and moreover the perception of oneself.

Endurance of Familial Relationship. Some participants neutrally evaluated the state of their family after the cheating occurred. The participants noted that there was no significant change between the family's dynamics and interaction with each other. It was expressed that their family was still the same before and after the infidelity. Some of the reasons given by Yeri, a female participant, for their particular familial relations is because the parent was away due to work and because the parents isolated the conflict from the children. In her words, she stated that "My father was a chair officer, he gets assigned to different places and ever since we were little."

Deterioration of Familial Relationship. While the aforementioned participants perceive the infidelity as a shared challenge of the family and viewed the results in a meaningful way, there are, however, a handful of participants who negatively evaluated the situation. Occurrences of hostility and violence against each other were expressed. The participants acknowledged the loss of communication between the members of their family and loss of connection even with extended family members. Hyacinth, Jessie, and David, the ones who were happily situated in their families before the infidelity, evaluated that the effects of the cheating having exerted a negative influence on their families. David talked about how chaotic it was in their home, and he stated that "I think it just made everything else worse. Because it made my mother more emotional, what happened was my mom would get angry at my dad. And my dad would get angry at my mom for being angry at him because he was really pretending that he did nothing wrong nor committed any cheating. And both of them would take out their anger on me." The hostility and anger in David's voice were evident while he was uttering that memory. Hyacinth expressed how it became so awkward in their household that nobody was engaging in any interactive nor enjoyable topics and was so careful not to mention the issue in their conversations because it was too sensitive. Her younger sister Jessie uttered the most coherent sentence that encompasses all the sentiments the participants had about the major changes that happened in their families. In her words, she said, "Our house, our house is merely a house, not a home."

\section{Post-Infidelity Mother-Child Relationship}

This section's attention is focused primarily on the perspective of the participant on their mother-child relationship after their discovery. The questions asked revolved around the type of relationship the participants had with their mothers after their discovery, how they see and describe their mothers and how intimate they are with each other. These questions were asked in order to bring to light the impacts of infidelity-cheating or cuckquean.

The parental infidelity experienced by the child resulted in hostility towards the mother, in the case of children whose mothers were the ones involved in the cheating. The children act civil and normal towards their mothers despite being angry at her. Among which the 
participants expressed the trust issues they developed towards the mother, which resulted in them not confiding in her about personal stories and problems. Jessie, who once treated her mother as a best friend, stated that she hated her to the point where all her problems pointed to the mother as a cause. Abigail also mentioned that she could not trust her mother anymore to the point where she does not update on where she is situated. "I no longer trust my mother, actually. I don't tell her where I'm going or what's happening in my life. I only tell her things when it's already happening or when she is needed. I don't know, and it's bad that we were not close, to begin with, and then she did that."

\section{Post-Infidelity Father-Child Relationship}

Abigail and Hunter reported that the relationship between their fathers was negatively affected by infidelity. The participants usually distanced themselves from their fathers and did not want to communicate with them anymore. They expressed their disbelief of how their father cheated and talked about their shattered beliefs and the shattered images of their fathers. In one case, where the father was the one being cheated on, Abigail distanced herself from her father because of her guilt for keeping the affair a secret from him and because she was afraid of possibly oversharing when talking with her father. She said, "I became a little distant to my father because I am scared to overshare and might delve into that topic. There is also a part of me that feels guilty because I know things. I also feel that I have betrayed tatay."

On the other hand, some participants reported that the father-child relationship became stronger, and they became closer with their fathers after the infidelity. The relationship was characterized by a new level of respect for the father and putting the child into the shoes of the father. In another case, the male participant was able to put himself in the shoes of his father and explained, in his perspective, why his father cheated on his mother. In one case, Hyacinth, despite being hurt and angry towards the father, was able to empathize with him and became more sensitive to what he felt at that time.

It is notable that the participants who positively reported their relationships with their fathers are no longer experiencing infidelity at the time of the interview. While the ones who negatively reported the relationship are still experiencing it.

\section{Post-Infidelity Sibling Dynamics}

The participants' relationship with their siblings was also noted. The effects of parental infidelity in the relationship of the participants with their siblings were evaluated as extremely positive. All of the participants reported that they became closer as siblings. The siblings can now confide with each other and are able to have meaningful conversations and interactions. Most of the reasons given were because siblings became the support system of the participants. Others stated that the siblings became closer by looking out for each other, and some grew closer due to maturity. Yeri, who is the oldest among her siblings, stated that "I had to be strong, I had to be the rock for my siblings because they were still so young, I believe that they are not supposed to and should not get to experience what I was experiencing, they should not see what I was seeing." Moreover, Jessie shared that due to the absence of both parents, the siblings' relationship became closer. She uttered that she was grateful to have her siblings with her. They considered each other as their support systems. Jessie once described the relationship between her siblings as not too close, wherein they do not share personal matters with each other but can have fun together. It is of particular interest that despite the infidelity happening inside the households of the participants, sibling companionship managed to grow stronger. 


\section{Relationship with Friends Post-Infidelity}

It was also evident that the impact of parental infidelity greatly affected the way the participants behaved around their friends and what they considered their friends as. Questions were asked in order to bring to light the different interpersonal relationships of the participants aside from their intermediate family at home. The participant's relationship with friends became more mature and beneficial to the well-being of the participants. The participants confided in friends that had similar experiences with parental infidelity. They continued their role as a protector, not only in the family but also with their friends as well. In one case, the participant became overprotective of their friends and the relationships her friends were involved in. The participants also assumed the role of the protected at times when they needed comfort and advice for their problems. Jessie, who openly admitted that she underwent a stage of depression because of the infidelity, stated that her friends helped her with it by becoming one of her primary support systems.

\section{Psychological Effects of Parental Infidelity on the Child}

Neglecting Academic Obligations. The academic obligations of a student may involve maintaining progress in assigned work, reporting to class and participating actively, and engaging and responding in academic discussions. Sean described how he lost the responsibility and enthusiasm in his academics which led to his remarks reporting as unsatisfactory. He stated that infidelity "negatively affected my studies." Hyacinth and Jessie, who were once high achievers in school, reported having poor academic performance postinfidelity. However, there are some participants like Jay and Natalie who focused more on their academics and studied as a way of taking their minds off of things. In any relationship, being exposed to infidelity can have short-term and long-term consequences such as distress, leading to academic difficulties (Duncombe \& Marsden 2004).

Development of Trust Issues. Most participants (10 of 14 participants) expressed how they noticed that they developed trust issues rooting in the parent's infidelity. They recounted how they would not fully invest themselves and would only trust with reservations. Some participants stated trust issues from both friends and romantic relationships, and other participants stated that they have trust issues only in romantic relationships.

"It imo trust may reservation ka ba kay kay feeling ko hiya geap kay ito ngani nga, hera ngani mag asawa na, tas may anak na, so bagat umabot na bat hera na point na maiha na, tas amo la nagsugad la geap, asay pa ba it mag jowa jowa la." [My trust is now quite reserved because I even see married husbands and wives with kids that end up badly, how much more for boyfriends and girlfriends.] - Abigail

Lester was among the participants who did not mention developing trust issues, rooting from the fact of his extensive rationalization.

Development of Commitment Issues. Aside from the development of trust issues, participants also expressed how they became cautious and less interested in involving themselves in romantic relationships. The participants reasoned out how they would be less likely to be involved with a significant other due to the possibility of committing to the wrong person or having someone better for them. One participant expressed how, despite being courted by many guys, she would only engage in a dating type of relationship and not a serious one. In one account, the participant only engages in a relationship that does not have a label and sees the guy more as a companion than a lover. 
"Mayda ako constant fear na diri ko aw diri ako magcocommit kay maybe mag eend up ako with someone like my father, sugad hito so permi gud ito bagat amo itot, bagat hindrance kun kayano diri ako nagcocommit ha someone.' [I have a constant fear of committing myself into a relationship because I do not want to end up with someone like my father. In such a way, this thinking becomes a hindrance for me to commit.] -Yeri

Infidelity is considered one of the most devastating betrayals and violations of trust that a person may suffer. Some people are indirectly affected by the violation of trust, namely their children. Betrayal causes children to lose their trust and confidence in the world because they perceive it as unpredictable and threatening. (Whisman \& Wagers, 2005; Sori 2007)

Possible Celibacy. Studies have shown that children of unfaithful parents are reluctant to start and keep a relationship, fearful that their parents would fall in love with someone else (Batara et al. 2018).

Two female participants, as a result of their developed trust issues and commitment issues, cannot see themselves getting involved in a serious romantic relationship in the future. They stated that they were not interested in marrying a person in the future but expressed wanting to have kids. The participants feel that getting married will give you the possibility of getting cheated on than not being in a marriage.

\begin{abstract}
"Gosh, di ko pa ini pinag isipan, pwede ba yun. *pause* ma duha nga anak, duha la, makapoy it lima, duha nga adopted, mga sugad. Pero sure ako na if adopted it usa, adopted hera nga duha, diri ito pwede nga usa la." [Gosh, I have not really that of this *pause* two children, just two, five is too tiring- two adopted. But I am sure if the other one is adopted, the second should be adopted too.] -Jay
\end{abstract}

\title{
Impacts of Parental Infidelity on the Participants' Self-concept
}

This sub-theme comprises the effects of parental infidelity on how the individual perceives oneself, values self, and envisions his or her ideal future.

Self-image. Self-image goes deeper than anything a person sees when they look into a mirror, and it goes beyond the physical manifestations of oneself. Noting the impacts of infidelity on the participants' self-image is important as it can affect one's self-esteem, and experiences of parental infidelity may build up one's impressions about the self.

Few of the participants ( 3 of 14 participants) perceived infidelity as some form of transcendence in which they can rise above the unfortunate situation. Looking back at the experience, Jay reported that she is now stronger than she was before. In her words, she said, "I was able to survive it." Hyacinth also believes that the situation made her stronger, "I became stronger." In the process, she was also able to question her mother's teachings, in which she was able to empower herself by making her own decisions and maintain sanity. Jessie shared that she is able to protect herself from the people who hurt her, consciously or unconsciously, by building emotional walls around her. She shared how the infidelity deeply hurt her and that to be able to defend and shield herself from further damages, the metaphorical wall she put up serves as protection which buffers herself from undergoing negative emotional outcomes.

Self-esteem. As people go through life, their self-esteem rises and falls. In this study, these fluctuations in their self-esteem reflect changes in the family environment they live in. The participants noted how infidelity affected how they value themselves. The majority of the participants referred to infidelity as the reason why they started to value themselves more, and they believe that they are not worth the pain and suffering of being cheated on. In one account, the participant learned to love herself more after the affair happened. She expressed how she would not want to experience the same thing knowing how common it has gotten. 
"I realized na kailangan mo la talaga hin self-worth para malampasan ito nga imo na fefeel." [I realized that you just need self-worth in order to get through things.] -Jessie

"Mas ginvavalue ko an akon self yana kay I recognize my, I have my own importance to my family. To mama." [I value myself more right now because I recognize my importance to the family, especially to my mama.] -Lester

David pointed out how the infidelity did not affect his self-worth, pointing to the fact that he always had low self-esteem from the beginning, even before the infidelity occurred in the family.

Despite these positive realizations given by some participants about the self, 3 out of 14 participants expressed how they valued themselves lesser than before. Jemari would care less about his health and shared that due to the infidelity, he started to drink and smoke and continue to do so to this day. Natalie, who felt sorry for being situated in a family of a cheating father, shared that her low self-esteem was brought about the infidelity. Hyacinth continues to give herself less importance which is coupled with suicidal ideations.

"Pagkita ko la ak sarili siguro waray man ini halaga bagan dire mo n ginahhatagan im sarili hin that much importance. Ready na ready ka na maligis kay feeling mo waray amo man la geap." [I see myself as worthless. It is like you are not giving yourself that much importance. At this point, you even think about going into a car accident because things would not change.] -Hyacinth

Ideal Future. Amato and Keith (1991) and Batara et al. (2018) pointed out that when the children discover their parent is unfaithful, they may be inclined to think poorly of themselves, which could lead to signs of depression. However, this is not the case for most of our participants. The participants, when asked about how they viewed their future self, more or less expressed how strongly they see themselves as not as their parents, regardless of being the one cheated on or being the cheater. They see themselves as better versions of their parents and of themselves. In the aspect of their future relationships, they also see themselves involved in a relationship not like their parents. In one account, the participant pointed out how he did not want the same love his parents had. The participants also see the ideal relationship as having better foundations and better communication.

"Napasok ako relationship pero na dire ako pag isip hin future stuff, especially when the guy talks about marriage. It's scary, scary talaga." [I go into relationships without giving too much thought about the future, especially when the guy talks about marriage. It really is scary.] -Jessie

"Worst case scenario. Mayda la gihap cases of infidelity." [... There are still occurrences of infidelity.]

-Lester

Hyacinth perceived her future as having pet animals at home and did not mention having a family in the near future. "Maygad feelilng ko damo it akon mga hayop tas alone." [My god, I have a feeling I would own lots of cats while I am alone.] -Hyacinth

\section{CONCLUSION}

Given the fact that most infidelity cases happen in a family context, the researchers find it interesting and significant to find out how parental infidelity affects the child. The child in 
these cases is merely a victim of their parent's behavior, and infidelity is paramount to a child's emotional and mental state because a child's well-being depends on the family environment he or she grows up in. This research's main purpose was to discover the impact of young adult Filipino children's discovery of their parents' infidelity on their self-concept. Driven by these thoughts, the researchers sought to (a) discover the experiences of adult children who were aware of the infidelity happening in their family, (b) explore the possible impact of parental infidelity on the child's self-concept, and (c) find out other possible psychological effects of the parental infidelity to the children involved in the marriage.

The researchers used purposive sampling to be able to reach participants who fit into the criteria given. There were seven male and seven female participants, aged 18-24, who have reportedly experienced or are experiencing parental infidelity. The majority of the participants have fathers as the cheating parent in the marital relationship, while three (3) female participants experienced parental infidelity from their mothers, two (2) of whom experienced infidelity from both parents. Extensive questions were asked about their experiences with their parents' infidelity in order to come up with the necessary responses to answer the research question, as well as gather the answers for the main objectives.

Using the theoretical rationale of the Family Systems Theory proposed by Murray Bowen and Self-Concept Theory by Rogers, the researchers were able to draw two major themes, which are the Family Dynamics Prior to the Infidelity and Impacts of Parental Infidelity. The findings that resulted from the study affirm the principles of the family systems theory, which states that a family is an emotional unit and creates systems that interact interdependently with each other. In relation to the research study, the families of the participants were gravely affected by a conflict that should supposedly only involve the dyadic relationship of the parents. It is important to note that infidelity affects the family both in positive and negative ways, which is deviant from the common notion that infidelity almost always affects the family negatively. Triangles were formed in the relationship between parents and children during the time of the discovery of infidelity. Most of the participants were able to differentiate themselves from the situation they were in. The participants were able to separate their negative feelings and emotions to infidelity from other interpersonal relationships. The absence of marital conflict in the family does not guarantee that the family would not experience parental infidelity as only one participant had a marital conflict present in her family. Dysfunction in one spouse can be considered as an affecting factor in the possibility of the family experiencing parental infidelity. Cases of impairment of one or more children exist in the family of the participants. The majority of the participants can be observed to be emotionally distant from the family during that time in order to reduce the familial tension he or she feels.

Due to the overwhelming emotional trauma and pain, most often than not, some betrayed parents overlook the fact that they sometimes project their anger and frustration towards the children rather than the unfaithful spouse. Similar to the emotional distance the researchers noted, the majority of the participants emotionally cut themselves off from any contact with their family members in an attempt to manage their familial problem. In the case of sibling positions, most of the participants were able to uphold the expected roles and traits that the family systems assigned them to. In the part of the societal emotional process, the researchers categorized this into two, one for friends and the other for romantic relationships. In the category of friends, the participants were able to cope and interact with them positively. The participants treat their friends as more of a family and as confidants. In the category of romantic relationships, the participants were not able to cope and interact with them positively. The participants see their romantic relationships as a potential risk and bring up a higher chance for them to experience the same as what their parents experienced. 
There is an evident pattern between the number of times the parent cheated on the spouse and the reason/s behind their infidelities. Those cheating parents with multiple affairs are perceived by their children as having sexual intentions for the reason of their cheating, whereas those cheating parents who only cheated once had a slightly more positive perception from their children. Among the perceived reasons are comfort, companionship, and curiosity. The initial reactions of the participants were mostly negative in nature. The participants felt angry and confused about what had taken place. They cried and denied the fact that one of their parents cheated on another. Some of the participants even thought about violent actions, such as punching and stabbing, towards their cheating parents. The manner in which the participants discovered the infidelity affected the gravity of the emotional effect it had on them. Those who first-handedly saw the affair happening experienced more negative and serious emotional damages such as depression and extreme anger. Those who heard the news from their mother created more possibilities for triangles to form into their family.

In the topic of how infidelity changed the participants' notion of themselves, the discovery of the infidelity resulted in the development of negative perceptions of the participants towards themselves. The participants feared becoming like their cheating parents. The infidelity also had an effect on the participants' self-worth. The majority of the participants were observed to have low self-worth due to the ideas of replaceability and shamefulness for what has happened to them. In terms of their ideal selves, most of the participants were able to envision themselves with a bright future.

\section{Recommendations}

The study's current findings and limitations may have future implications in the field of research on parental infidelity and its impact on children. Below are the proposed recommendations constructed by the researchers:

Limitations. Certain limitations of the study may have contaminated or impacted the results and conclusion of the current study. Therefore, the researchers have noted the following limitations: first, the small sample at hand and the results generated from the participants may not be able to generalize the experience to the population. Second, the researchers only had one (1) academic year to look for participants, analyze, and finalize the results of the study. Therefore, access to samples limited the researchers to conduct the study in Tacloban City, where the researchers are situated, and participants can be conveniently extracted. Third, the study does not consistently differentiate treatment recommendations by age. Consistently, Snyder (2005) believe that there are discrepancies to the participants' responses to parental infidelity (i.e., by age, gender, type of infidelity, pre-infidelity family structure) and that these aforementioned factors should be carefully examined so that future clinicians and/ or therapists may be able to identify the best treatment practices for families who are faced with parental infidelity. Fourth, the participants' mood may influence their answers during the interview. Fifth, the study was limited to observing and analyzing the problem in a qualitative approach. The researchers noted that rigorous qualitative research paired with quantitative studies is needed in order to provide a more comprehensive understanding of the impact and treatment of parental infidelity. Sixth, response bias was noted during the conceptualization of the interview schedule and the formal interview itself. The questions were centered on parental infidelity, and the topic may have been carried over to other questions pertaining to the state of the individual without having to consider infidelity. Some questions may also lead participants to answer a certain way. Lastly, the researchers' personal biases such as confirmation and observer-expectancy bias were noted.

Future Studies. Given the findings above, the researchers have noticed that there were few rising themes that could have made the research more in-depth or could be a potential 
research topic in the future. Knowing that the participants went through a process of grief and anger, the researchers would like the future potential researchers to explore the process of forgiveness of the participants and whether or not it could contribute to a better and more positive self-concept after a stressful event. The researchers also took notice of one participant who belonged to a resilient family, which is why the researchers recommend the future researchers explore the topic of resiliency among families who experienced parental infidelity. There should be an emphasis on the role of resiliency in the family's healing process and whether or not this would affect how their child sees the stressful event. While working on the various family systems in the family, the researchers would also recommend future researchers to explore the changes in the person's attachment style and whether or not the attachment style between one's parent would be carried over to his or her other interpersonal relationships.

Practical Value. The findings of this research would be extremely beneficial to the development of a family therapy system for those families who experienced parental infidelity. The questions used for the interview schedule of this research could be utilized to be used as interview questions that would help in the client's discovery of the changes in his/her selfconcept. There is a positive outcome from the interview questions. The participants were able to realize something about themselves and how much parental infidelity changed them. Furthermore, the use of the family systems theory and its integration into the research questions would be of great help for therapists to go through the effects of parental infidelity in the family. This would be extremely helpful in locating which part of the family systems the therapists should focus upon or where to start his or her treatment.

\section{ACKNOWLEDGEMENTS}

We would like to express our sincere gratitude to the primary editor and editorial board. We would also like to extend our appreciation to the reviewers for sharing their insights and expertise to improve our research paper. Moreover, this research received no funding from any public, commercial, or nonprofit organizations.

\section{REFERENCES}

Abalos, J.B. 2011. Determinants of Men's Extramarital Sexual Experience in the Philippines. Philippine Population Review 10(2): 51-74.

Abbott, D.A., S.L. Cramer, and S.D. Sherrets. 1995. Pathological gambling and the family: Practice implications. Families in Society 76(4): 213-219. doi:10.1177/104438949507600402

Amato, P.R., and B. Keith. 1991. Parental divorce and adult well-being: A meta-analysis. Journal of Marriage and Family 53(1): 43-58.

Arellano-Carandang, M.L. 1995. Filipino children under stress: Family dynamics and therapy. Quezon City, Philippines: Ateneo University Press.

Arnett, J.J. 1995. Broad and Narrow Socialization: The Family in the Context of a Cultural Theory. Journal of Marriage and the Family 57(3): 617. doi: 10.2307/353917

Atkins, D.C., D.H. Baucom, and N.S. Jacobson. 2001. Understanding infidelity: Correlates in a national random sample. Journal of Family Psychology 15: 735-749. Doi:10. 1037/0893-3200.15.4.735.

Batara, J.B.L., A.B. Guanzon, J.L. Macaloyos, C.L. Diaz, J.C. Albao, and M.D. Villano. 2018. Parental Infidelity and Children's Reactions: A Case Study in a Filipino Family. Prism 23(1). 
Bavelas, J., and L. Segal. 1982. Family Systems Theory: Background and Implications. Journal of Communication. $101-102$. http://web.uvic.ca/psyc/bavelas/1982famsystsR.pdf

Bowen, M. 1978. Family therapy in clinical practice. New York: Aronson. https://www.jstor.org/stable/30015706

Bradbury, T.N., and R.L. Weiss. 2006. The developmental course of marital dysfunction. Cambridge University Press. https://peplau.psych.ucla.edu/wpcontent/uploads/sites/141/2017/07/Hill-Peplau-98.pdf

Braun, V., and V. Clarke. 2006. Using thematic analysis in psychology. Qualitative research in psychology 3(2):77-101. doi:10.1191/1478088706qp063oa

Brown, E. 1991. Patterns of infidelity and their treatment. New York: Brunner/Mazel. doi:10.4324/9780203782743

Browning, D. 2003. Can Marriage Be Defined?. Word and World 23(1): 5-14. http://wordandworld.luthersem.edu/content/pdfs/23-1_defining_marriage/231_browning.pdf

Callander, M. 2015. Children Of Infidelity-How They Hurt, And How They Heal. Kindred Media. https://kindredmedia.org/2015/06/children-of-infidelity-how-they-hurt-andhow-they-heal/ (accessed April 2, 2021)

Duncombe, J., and D. Marsden. 2004. Affairs and Children. In The state of affairs: Explorations in infidelity and commitment, ed. J. Duncombe, K. Harrison, G. Allan, \& D. Marsden, 187-201. Mahwah, NJ: Lawrence Erlbaum.

De Castro-Bofill, F.R., M.J. Barrameda, M.C. Dadivas, E.R. Panganiban, and A.C. San Jose. 2016. Living within a broken vow: The impact of parental infidelity among late adolescents in establishing romantic relationships. Universal Journal of Psychology 4(5): 228-35. doi:10.13189/ujp.2016.040503

Divecha, D. 2014. What Happens to Children When Parents Fight? Developmental Science. https://www.developmentalscience.com/blog/2014/04/30/what-happens-to-childrenwhen-parents-fight (accessed April 2, 2021)

Duncombe, J., and D. Marsden. 2004. Affairs and children. In The state of affairs: Explorations in infidelity and commitment, ed. J. Duncombe, K. Harrison, Allan, \& D. Marsden (Eds.), 187-201. Mahway, NJ: Lawrence Erlbaum Associates Inc.

Enrique, J., H. Howk, and W. Huitt. 2007. An overview of family development. Educational Psychology Interactive. Valdosta, GA: Valdosta State University.

Espina, E.G.F. 1996. Mother-child relationships in the Philippines. Philippine studies 44(2):153-174.

Fife, S.T., G.R. Weeks, and N. Gambescia. 2008. Treating Infidelity: An Integrative Approach. The family journal: counseling and therapy for couples and families 16(4): 316-323. https://doi.org/10.1177/1066480708323205.

Garo-Santiago, M. A., R. Mansukhani, and R. Resurreccion. 2009. Adolescent identity in the context of the Filipino family. Philippine Journal of Psychology 42(2): 175-193.

Gillett, R. 2016. 11 ways your marriage could be affecting your kids' success. Business Insider. https://www.businessinsider.com/how-your-marriage-influences-your-childs-success2016-8 (accessed April 2, 2021)

Goga, C.I., and A.M. Niţă. 2019. Romania in the European Context: Social and Legal Effects of the Matrimonial Property Regimes in Contemporary Society. Revista de Stiinte Politice, (64): 35-52.

Gonzales, T., S.J. Greer, N.J. Scheers, E. Oakes, and J. Buckley. 2004. "Sources of Resilience in the Filipino Wife's Responses to Spousal Infidelity." Philippine Journal of Psychology 37(1): 74-103. 
Greene, K. H. (2006). Awareness of parental infidelity on college students' reported commitment in romantic relationships. Dissertation Abstracts International-B $68(02): 1-122$

Haefner, J. 2014. An Application of Bowen Family Systems Theory. Issues in Mental Health Nursing 35(11):835-841. doi:10.3109/01612840.2014.921257

Hafen, B.C. 1983. The constitutional status of marriage, kinship, and sexual privacy: Balancing the individual and social interests. Michigan Law Review 81(3): 463-574. doi: $10.2307 / 1288509$

Harter, S. 1983. Developmental perspectives on the self-system. In Handbook of child psychology, Vol. 4, Socialization, personality, and social development, ed. M. Hetherington, 275-385. New York: Wiley.

Harter, S. 1988. Developmental processes in the construction of the self. In Integrative processes and socialization: Early to middle childhood, ed. T.D. Yawkey and J. E. Johnson, 45-78. Hillsdale, NJ: Erlbaum.

Hertlein, K.M., J.L. Wetchler, and F.P. Piercy. 2005. An Overview: Infidelity. Journal of Couple \& Relationship Therapy: Innovations in Clinical and Educational Interventions 4(2-3): 5-16. https://doi.org/10.1300/J398v04n02_02

Howe, N., H.S. Ross. 1990. Socialization, perspective-taking, and the sibling relationship. Developmental Psychology 26(1):160-165. doi:10.1037/0012-1649.26.1.160

Kerr, M. 2000. One Family's Story: A Primer on Bowen Theory. The Bowen Center for the Study of the Family. https://thebowencenter.org/theory/ (accessed April 2, 2021)

Lee, G. 2015. "Have a break, have an affair?" In Manilastandard.net. https://manilastandard.net/mobile/article/167613 (accessed April 2, 2021)

Leonard, K. E. 2002. Alcohol and substance abuse in marital violence and child maltreatment. In The violence and addiction equation: Theoretical and clinical issues in substance abuse and relationship violence, ed. C. Wekerle \& A.M. Wall, 194-219. New York: Brunner-Routledge.

Lerman, R.I. 2002. How do marriage, cohabitation, and single parenthood affect the material hardships of families with children?. Urban Institute. http://webarchive.urban.org/publications/410539.html.

Liwag, M.E.C.D., S. Alma, and M.E.J Macapagal. 1998. How we raise our daughters and sons: Child-rearing and gender socialization in the Philippines. Philippine Journal of Psychology 31(1): 1-46.

Lusterman, D.D. 2005. Helping Children and Adults Cope with Parental Infidelity. Journal of Clinical Psychology 61(11): 1439-1451. doi: 10.1002/jclp.20193.

Margolin, G., and V. Fernandez. 1985. Marital dysfunction. In Handbook of clinical behavior therapy with adults, 693-728. Boston, MA: Springer. https://doi.org/10.1007/978-14613-2427-0_25

Maslow, A. H. 1956. A philosophy of psychology. In Humanistic viewpoints in psychology. ed. F.T. Severin, 17-33. New York: McGrawHill

Montemayor, R., and M. Eisen. 1977. The development of self-conceptions from childhood to adolescence. Developmental Psychology 13(4): 314-319. doi:10.1037/00121649.13.4.314

Negash, S., and M.L. Morgan. 2015. A Family Affair: Examining the Impact of Parental Infidelity on Children Using a Structural Family Therapy Framework. Contemporary Family Therapy 38(2): 198-209. doi. 10.1007/s10591-015-9364-4

Nogales, A. 2009. Parents who cheat. How children and adults are affected when their parents are unfaithful. Florida: Health Communication 
Ong, A., P. Poon, S. Sibya, and E. Macapagal. 2014. Gender, adult attachment styles, and the tendency to commit dating infidelity: A mixed methods study. Phillippine Journal of Psychology 47(11): 93-116.

Osika, A. 2017. Inter-rater Reliability (IRR): A Valuable Metric for Qualitative Research. https://smokefree.gov/mhealthmonitor/inter-rater-reliability-irr-valuable-metricqualitative-research (accessed April 2, 2021)

Peluso, P.R. 2007. Infidelity: A practitioner's guide to working with couples in crisis. Routledge.

Pepler, D.J. and W.M. Craig. 1998. Assessing children's peer relationships. Child Psychology and Psychiatry Review 3(4):176-182.

Pescitelli, D. 1996. An analysis of Carl Rogers' theory of personality. http://pandc.ca/?cat=carl_rogers\&page=rogerian_theory (accessed April 2, 2021)

Rosenberg, M. 1979. Conceiving the self. New York: Basic Books.

Salafia, B., M. K. Schaefer, and E. C. Haugen. 2013. Connections between marital conflict and adolescent girls' disordered eating: Parent-adolescent relationship quality as a mediator. Journal of Child and Family Studies 22: 1-11. doi:10.1007/s10826-0139771-9.

Schnarch, D. M. 1991. Constructing the sexual crucible: An integration of sexual and marital therapy. New York: WW Norton \& Company.

Schneider, J.P., R. Weiss, and C. Samenow. 2012. Is it really cheating? Understanding the emotional reactions and clinical treatment of spouses and partners affected by cybersex infidelity. Sexual Addiction \& Compulsivity 19(1-2): 123-139. doi:10.1080/10720162.2012.658344

Schonian, S. 2013. Perceptions and Definition of Infidelity: A Multimethod Study. University of Nevada Las Vegas. UNLV Theses, Dissertations, Professional Papers, and Capstones. 2026. http://dx.doi.org/10.34917/5363941

Schwartz, S.H. 1977. Normative influence on altruism. In Advances in experimental social psychology, ed. Berkowitz, 221-279. New York: Academic Press

Simpkins, S. D., H. Weiss, K. McCartney, H. Kreider, E. Dearing. 2006. Mother - Child Relationship as a Moderator of the Relation Between Family Educational Involvement and Child Achievement. Parenting: Science and Practice 6(1):4957. doi:10.1207/s15327922par0601 2

Sori, C. F. 2007. "An affair to remember": Infidelity and its impact on children. In Infidelity: A practitioner's guide to working with couples in crisis, ed. P.R. Peluso, 247-276. New York, US: Routledge/Taylor \& Francis Group.

Stangor, C., H. Tarry, and R. Jhangiani. 2014. Close Relationships: Liking and Loving over the Long Term. Principles of Social Psychology-1st International Edition.

Torres, A. T. 1995. Re-thinking the Filipino family: Tracking changes across the years. In the Filipino Family: A spectrum of views and issues, ed. A. E. Perez, 136-148. Quezon City, Philippines: University of the Philippines Press.

Wallerstein, S., and J.B. Kelly. 1980. Effects of divorce on the visiting father-child relationship. The American Journal of Psychiatry, 137: 1534-1539. doi:10.1176/ajp.137.12.1534

Wamboldt, F., and D. Reiss. 1989. Task performance and the social construction of meaning: Juxtaposing normality with contemporary family research. In Normality: Context and theory, ed. D. Offer \& M. Sabshin, 2-40. New York: Basic Books.

Wardle, L. D. 2002. Parental infidelity and the 'no-harm' rule in custody litigation. Catholic University Law Review 52: 81-132. http://ssrn.com/abstract=397660 
Whitty, M.T., and L.L. Quigley. 2008. Emotional and sexual infidelity offline and in cyberspace. Journal of Marital and Family Therapy 34(4): 461-468. doi:10.1111/j.1752-0606.2008.00088.x

Whisman, M. A., and T. P. Wagers. 2005. Assessing relationship betrayals. Journal of Clinical Psychology 61(11):1383-1391.

Wimalasena, N. 2016. An Analytical Study of Definitions of the Term "Marriage". International Journal of Humanities and Social Science 6(1): 166-174.

Young, K.S., E. Griffin-Shelley, A. Cooper, J. O'mara, and J. Buchanan. 2007. Online infidelity: A new dimension in couple relationships with implications for 106 evaluation and treatment. The Journal of Treatment and Prevention 7(1-2): 59- 74. https://doi.org/10.1080/10720160008400207

\author{
ANDREW SIGUAN* \\ Leyte Normal University \\ Paterno Street \\ Tacloban City, Philippines
}

MAXIN FENONI THERESE M. ONG

Leyte Normal University

Paterno Street

Tacloban City, Philippines

SIDNEY IRA MARIE B. CAÑETE

Leyte Normal University

Paterno Street

Tacloban City, Philippines

*Corresponding author: andrew.siguan@lnu.edu.ph

Received: 4 June 2021 / Accepted: 29 September 2021/ Published: 20 November 2021 